ing it up is saved many times over by the facility with which reference is made.

Charles S. Crandall.

The State Agricultural College, Fort Collins, Colorado.

ZONE TEMPERATURES.

MY attention has been recently called by Dr. Walter H. Evans, of the United States Department of Agriculture, to an error in the temperature tables accompanying my paper on the 'Laws of Temperature Control of the Geographic Distribution of Animals and Plants,' an abstract of which was printed in my recent bulletin on 'Life Zones and Crop Zones.' The error in question relates to the effective temperature or 'sum of normal mean daily temperature above $6^{\circ} \mathrm{C}$.' In the tables bearing the above heading the quantities actually given are the sums of normal mean daily temperatures (without deducting the $6^{\circ} \mathrm{C}$. each day) for the period during which the mean daily temperature exceeds $6^{\circ} \mathrm{C}$.

The temperature data, as stated on the first page of my original paper, were furnished by the Weather Bureau. Not being of a mathematical turn of mind, I did not detect the error until my attention was called to it by Dr. Evans. Corrected tables will be given in the next edition of 'Life Zones and Crop Zones.'

C. Hart Merriam.

\section{PHYSICAL NOTES.}

Dr. Oliver Lodge, in a recent paper before the Institution of Electrical Engineers, speaks of the probable importance of leakage currents in the usual methods of telegraphing by magnetic inductance through space. This form of wireless telegraphy has usually been accomplished with long parallel wires on poles and ground returns. In some experiments made by Stephenson near Edinburgh horizontal coils of wire were used and signals transmitted half a mile with a morse key in one coil and a telephone receiver in the other. Mr. Lodge used similar coils covering areas of about 4,500 square yards and transmitted signals about two miles. The characteristics of his method are the use of an alternating current of a rather high frequency, about 380, and the tuning of the line to this frequency by the use of con- densers, that is, the balancing of the inductance so that the current becomes equal to the induced E. M. F. divided by the ohmic resistance. As a result, he gets much greater effects than where the current is principally determined by the inductance of the circuits. This he shows by mathematical determination will be the case, the value of $2 \pi x$ the frequency, coming in one instance in the denominator, while in the other it comes in the numerator of the expression giving the ratio between the secondary current and the impressed primary E. M. F.

F. C. C.

CURRENT NOTES ON METEOROLOGY.

THE WINDWARD ISLANDS HURRICANE OF SEPTEMBER, 1898.

THe practical advantages gained by the establishment of the new West Indian Service of our Weather Bureau are forcibly illustrated in the account of the hurricane of September 10th and 11th last, published in the September number of the Monthly Weather Review. The Weather Bureau Observer at Bridgetown, Barbados, sent a special cable to Washington at 12:40 p. m., September 10th, announcing the approach of a hurricane. Warnings were immediately cabled to Weather Bureau stations in the Lesser Antilles, and the officials in charge were directed to give the widest possible distribution to the warnings. Advisory messages were sent to other islands, as far west as Jamaica and eastern Cuba, to points on the South American coast of the Caribbean Sea, and to Admiral Watson's fleet, lying in the harbor of Caimanera, Cuba. The careful reports of the Weather Bureau Observers at Kingston, Jamaica, at St. Kitts and other stations also made possible an early and complete record of the hurricane.

In this connection another paper, in the same number of the Review, is of interest. It concerns the telegraph service of the Weather Bureau with the West Indies, and is illustrated by a chart showing the routes of the submarine cables over which reports are transmitted and the points at which the cables connect with the land lines.

At the December meeting of the Royal Meteorological Society (London) Captain A. Carpenter, R. N., gave an account of this disastrous hurricane. 